\title{
Low Annexin A1 expression predicts benefit from induction chemotherapy in oral cancer patients with moderate or poor pathologic differentiation grade
}

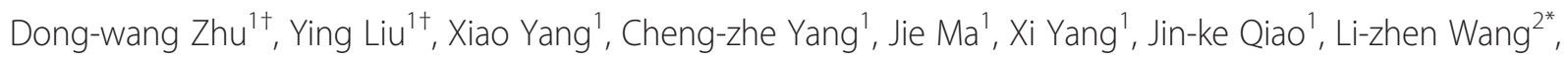
Jiang Li ${ }^{2}$, Chen-ping Zhang ${ }^{1}$, Zhi-yuan Zhang ${ }^{1}$ and Lai-ping Zhong ${ }^{1 *}$

\begin{abstract}
Background: The benefit of induction chemotherapy in locally advanced oral squamous cell carcinoma (OSCC) remains to be clearly defined. Induction chemotherapy is likely to be effective for biologically distinct subgroups of patients and biomarker development might lead to identification of the patients whose tumors are to respond to a particular treatment. Annexin A1 may serve as a biomarker for responsiveness to induction chemotherapy. The aim of this study was to investigate Annexin A1 expression in pre-treatment biopsies from a cohort of OSCC patients treated with surgery and post-operative radiotherapy or docetaxel, cisplatin and 5-fluorouracil (TPF) induction chemotherapy followed by surgery and post-operative radiotherapy. Furthermore we sought to assess the utility of Annexin A1 as a prognostic or predictive biomarker.

Methods: Immunohistochemical staining for Annexin A1 was performed in pre-treatment biopsies from 232 of 256 clinical stage III/IVA OSCC patients. Annexin A1 index was estimated as the proportion of tumor cells (low and high, $<50 \%$ and $\geq 50 \%$ of stained cells, respectively) to Annexin A1 cellular membrane and cytoplasm staining.

Results: There was a significant correlation between Annexin A1 expression and pathologic differentiation grade $(\mathrm{P}=0.015)$ in OSCC patients. The proportion of patients with low Annexin A1 expression was significantly higher amongst those with moderate/poorly differentiated tumor (78/167) compared to those with well differentiated tumor (18/65). Multivariate Cox model analysis showed clinical stage $(P=0.001)$ and Annexin $A 1$ expression $(P=0.038)$ as independent prognostic risk factors. Furthermore, a low Annexin A1 expression level was predictive of longer diseasefree survival $(P=0.036, H R=0.620)$ and locoregional recurrence-free survival $(P=0.031, H R=0.607)$ compared to high Annexin A1 expression. Patients with moderate/poorly differentiated tumor and low Annexin A1 expression benefited from TPF induction chemotherapy as measured by distant metastasis-free survival ( $P=0.048, H R=0.373$ ) as well as overall survival $(P=0.078, H R=0.410)$.

(Continued on next page)
\end{abstract}

\footnotetext{
* Correspondence: wanglizhen9th@hotmail.com; zhonglp@hotmail.com

${ }^{\dagger}$ Equal contributors

²Department of Oral Pathology, Ninth People's Hospital, College of

Stomatology, Shanghai Jiao Tong University School of Medicine, No.639

Zhizaoju Road, Shanghai 200011, China

'Department of Oral \& Maxillofacial-Head \& Neck Oncology, Ninth People's

Hospital, College of Stomatology, Shanghai Jiao Tong University School of

Medicine, No.639 Zhizaoju Road, Shanghai 200011, China
} 
(Continued from previous page)

Conclusions: Annexin A1 can be used as a prognostic biomarker for OSCC. Patients with moderate/poorly differentiated OSCC and low Annexin A1 expression can benefit from the addition of TPF induction chemotherapy to surgery and post-operative radiotherapy. Annexin A1 expression can potentially be used as a predictive biomarker to select OSCC patients with moderate/poorly differentiated tumor who may benefit from TPF induction chemotherapy.

Keywords: Annexin A1, Oral squamous cell carcinoma, Induction chemotherapy

\section{Background}

Oral squamous cell carcinoma (OSCC) is the most common type of head and neck cancer. Patients with OSCC have poor clinical outcomes including treatment related organ dysfunction. The 5-year survival rate of OSCC patients is $50-60 \%[1,2]$. To improve the clinical management of OSCC patients, it is important to develop different treatment strategies and ways to determine which subgroup of patients respond mostly to various strategies. Currently, the most common treatment for patients with locally advanced and resectable OSCC is radical surgery followed by post-operative radiotherapy or chemoradiotherapy depending on the presence of high-risk features in the surgical specimen. Clinically, only clinical staging and pathologic differentiation grade are used to predict prognosis of OSCC patients [3-5]. Therefore, it is critical to understand the biological basis of OSCC and develop novel biomarkers that can help predict the prognosis and likelihood that a patient benefits from a particular treatment strategy.

Induction chemotherapy is regarded as an effective way to reduce locally advanced or aggressive cancers, to improve the chance of eradication of locoregional lesions by radical surgery and/or radiotherapy/chemoradiotherapy, and to preserve end-organ functionality to ultimately maintain a high quality of life. Recently, two randomized phase 3 trials (TAX323 and TAX324) demonstrated that induction chemotherapy protocol of docetaxel, cisplatin and 5-fluorouracil (TPF) combination followed by radiotherapy or chemoradiotherapy can improve overall survival (OS) compared to cisplatin and 5-fluorouracil (PF) in head and neck squamous cell carcinoma (HNSCC) patients [6-8]. However, it is still unknown whether TPF induction chemotherapy improves outcomes when given prior to surgery in patients with locally advanced HNSCC, especially OSCC. To address the role of induction TPF in OSCC treated with surgery, we conducted a randomized phase 3 trial of induction TPF followed by surgical resection versus surgical resection in patients with locally advanced OSCC [9]. We failed to demonstrate a survival advantage for induction chemotherapy in the overall study population. It is possible, however, that induction chemotherapy with TPF might improve outcomes in a molecularly defined subgroup of patients. Correlative studies from the aforementioned randomized trials could assist in identifying candidate biomarkers predictive of benefit from induction treatment.

Annexin A1 is an intracellular protein that can bind calcium and phospholipids. It has been suggested to have an important role in the inflammation response, cell proliferation, cell signaling, phagocytosis, and carcinogenesis [10]. Although there is still controversy regarding Annexin A1 expression in different types of cancers, including breast, pancreatic, hepatic, prostate, urothelial, cervical, and head and neck cancer [11-27], low Annexin A1 expression correlates with poor pathologic differentiation grade [11-15]. In fact, absence of Annexin A1 expression has been reported to correlate with a poor pathologic response to induction chemotherapy in breast cancer [28]. However, the clinical usefulness of Annexin A1 expression in OSCC is not well understood. Specifically, it is unknown if Annexin A1 expression in the pre-treatment biopsy from OSCC patients can be used as a prognostic biomarker or an indication for induction chemotherapy.

The aim of the present study was to evaluate Annexin A1 expression in the pre-treatment biopsy specimens from patients with resectable locally advanced OSCC. These patients had been enrolled in a randomized phase 3 trial of TPF induction chemotherapy followed by surgery and post-operative radiotherapy compared to surgery and post-operative radiotherapy. Furthermore we aimed to examine the possible prognostic and predictive role of Annexin Alexpression in this patient population. We hypothesize that low Annexin A1 expression plays a role in survival of patients with OSCC, and is also predictive of patient benefit from TPF induction chemotherapy.

\section{Methods \\ Patients}

256 patients with primary and locally advanced OSCC were enrolled in a prospective, randomized, phase 3 trial at Ninth People's Hospital, Shanghai Jiao Tong University School of Medicine [9], which was in compliance with the Helsinki Declaration. The aim of this study was to test the hypothesis that TPF induction chemotherapy administered prior to surgery and post-operative radiotherapy improves survival in patients with resectable locally advanced OSCC (trial registration ID: NCT01542931). After eligibility was confirmed and written informed consent 
obtained, patients were randomized to the control group (surgery followed by post-operative radiotherapy) or experimental group (TPF induction chemotherapy followed by surgery and post-operative radiotherapy).

The TPF induction chemotherapy consisted of docetaxel $75 \mathrm{mg} / \mathrm{m}^{2}$ intravenously and cisplatin $75 \mathrm{mg} / \mathrm{m}^{2}$ intravenously on day 1 , followed by 5 -fluorouracil $750 \mathrm{mg} / \mathrm{m}^{2} /$ day as a 120-hour continuous intravenous infusion on days 1 through 5. Induction chemotherapy was given every 3 weeks for 2 cycles. Surgery was performed at least 2 weeks after completion of induction chemotherapy, consisting of radical resection of the primary lesion and full neck dissection with appropriate reconstruction (pedicle or free flap); frozen sections during surgery was performed to confirm adequate margins. Post-operative radiotherapy was initiated 4-6 weeks after surgery, at a dose of 1.8-2 Gy/day, 5 days/week for 6 weeks, totally 54-60 Gy; in patients with high risk features, such as positive surgical margins, extracapsular nodal spread, or vascular embolism, a total radiation dose of $66 \mathrm{~Gy}$ was recommended.

Clinical tumor response to induction chemotherapy was determined by clinical evaluation and imaging studies (performed at baseline and 2 weeks after cycle 2 of induction chemotherapy). Responses were characterized according to the RECIST version 1.0 [29]. Pathologic response to TPF induction chemotherapy was assessed by examination of the resected specimen. A favorable response was defined as absence of tumor cells or presence of scattered foci of a few tumor cells (minimal residual disease with $<10 \%$ viable tumor cells), as previously described by Licitra et al. [30]; an unfavorable pathologic response was defined as the presence of $\geq 10 \%$ viable tumor cells in the resected specimen.

After treatment, patients were monitored every three months in the first two years, every six months in the subsequent 3-5 years, and once a year thereafter until death or data censoring.

\section{Detection of Annexin A1 expression using immunohistochemistry}

Pre-treatment formalin fixed and paraffin embedded biopsy specimens were used for detection of Annexin A1 expression; however, in the control group, if pretreatment biopsy was unavailable, resected surgical specimens were used. Sections of $4 \mu \mathrm{m}$ thick were studied using hematoxylin and eosin (HE) staining and immunohistochemical staining for Annexin A1. The HE sections were reviewed according to the WHO histological criteria [31]. Immunohistochemical staining was accomplished using well established methods as previously described [32,33]. In brief, after deparaffinization, endogenous peroxidase block and heat-induced epitope retrieval, primary rabbit polyclonal antibody to Annexin
A1 (product code of BA0640, Boster Biotech Co., Wuhan, China) at 1:150 dilution was added overnight at $4^{\circ} \mathrm{C}$, then visualized using 3,3'-diaminobenzidine (DAB) detection kit (Dako Cytomation, Denmark). The 1:150 dilution was the best dilution compared to 1:50, 1:100, and 1:200. Negative control was prepared using PBS instead of antibody. Microscopic examination was performed by two pathologists and all specimens were blinded. Positive staining for Annexin A1 expression was observed in the cellular membrane and cytoplasm. The Annexin A1 expression index was determined based on the proportion of stained cells on a scale of negative to strong as follows: negative, absence of stained cells; weak positive, $<50 \%$ of stained cells; and strong positive, $\geq 50 \%$ of stained cells. Low Annexin A1 expression was defined as negative and weak positive Annexin A1 expression, high Annexin A1 expression was defined as strong positive Annexin A1 expression. This was based on previous studies demonstrating that the chosen cut-off of $50 \%$ was reasonable for prognostic analysis [24].

\section{Statistical analysis}

The primary endpoint of this trial was survival rate. Second endpoints of this trial were local control and safety. Overall survival (OS) was calculated from the date of randomization to the date of death; disease-free survival (DFS)/locoregional recurrence-free survival (LRFS)/distant metastasis-free survival (DMFS) were calculated, respectively, from the date of randomization to recurrence/ locoregional recurrence/distant metastasis or death from any cause.

For descriptive analysis, categorical data were expressed as number and percentage. Chi-square test was applied to compare the difference between the baseline factors and Annexin A1 expression. The survival analysis was conducted using the Kaplan-Meier method and logrank test. Hazard ratios (HR) were calculated using the Cox proportional hazards model. Intention-to-treat principle was applied for efficacy analysis.

All hypothesis-generating tests were two-sided at a significance level of 0.05. Data were analyzed with the statistical software SPSS13.0 for Windows (SPSS Inc., USA).

\section{Results}

\section{Annexin A1 expression in OSCC patients}

From 03/2008 to $12 / 2010,256$ eligible patients were enrolled in this trial (128 patients in each group). 232 (91\%, 127 patients in the control group, 105 patients in the experimental group) patients were assessed for pretreatment tumor Annexin A1 expression levels. Table 1 summarizes their baseline clinical characteristics, with no significant imbalance between the two groups. 96 specimens (56 in the control group and 40 in the 
Table 1 Baseline characteristics and Annexin A1 expression

\begin{tabular}{lcccc}
\hline Characteristics & Total & \multicolumn{2}{c}{ Annexin A1 expression } & \\
\cline { 3 - 4 } & patients & Low & High & $\mathrm{P}$ \\
$\mathrm{N}=256$ & $\mathrm{~N}=96$ & $\mathrm{~N}=136$ & value* \\
$\mathrm{n}(\%)$ & $\mathrm{n}(\%)$ & $\mathrm{n}(\%)$ &
\end{tabular}

Gender

Male

Female

Age (years)

$\begin{array}{lllll}<60 & 168(65.6) & 67(71.1) & 90(64.4) & 0.562 \\ \geq 60 & 88(34.4) & 29(29.9) & 46(35.6) & \end{array}$

Site

Tongue

Buccal

$$
113(44.1)
$$$$
42(42.1)
$$$$
56 \text { (42.4) }
$$

Gingiva

45 (17.6)

$15(17.5)$

$28(20.3)$

Floor of mouth

Palate

40 (15.6)

$11(12.3)$

$27(21.1)$

$18(7.0)$

16 (16.7)

$13(8.5)$

$7(6.1)$

$7(5.9)$

Retromolar trigone

$10(3.9)$

$5(6.1)$

$5(2.5)$

Clinical T descriptor

$\begin{array}{lcccc}\text { T1/T2 } & 66(25.8) & 23(24.6) & 38(28.0) & 0.497 \\ \text { T3/T4 } & 190(74.2) & 73(75.4) & 98(72.0) & \\ \text { Clinical N descriptor } & & & & \\ \text { N0 } & 110(43.0) & 40(39.5) & 59(45.8) & 0.480 \\ \text { N1 } & 94(36.7) & 33(39.5) & 53(34.7) & \\ \text { N2 } & 52(20.3) & 23(21.0) & 24(19.5) & \end{array}$

Clinical stage

$\begin{array}{lcccc}\text { III } & 177(69.1) & 60(65.8) & 100(72.0) & 0.074 \\ \text { IVA } & 79(30.9) & 36(34.2) & 36(28.0) & \end{array}$

Pathologic differentiation

$\begin{array}{lcccc}\text { Well } & 80(31.2) & 18(22.8) & 47(33.1) & 0.015 \\ \text { Moderately } & 165(64.5) & 71(71.1) & 85(63.6) & \\ \text { Poorly } & 11(4.3) & 7(6.1) & 4(3.4) & \\ \text { Smoking status** } & & & & \\ \text { Current/former } & 126(49.2) & 52(56.1) & 58(39.0) & 0.084 \\ \text { Never } & 130(50.8) & 44(43.9) & 78(61.0) & \end{array}$

Alcohol use $e^{* * *}$

Positive $\quad 98(40.6) \quad 44(48.2) \quad 44(28.0)$

* $P$ value from the chi-square test was reported to compare the difference between low and high Annexin A1 expression based on the different baseline factors.

**Former/current smokers defined as at least a one pack-year history of smoking.

***Positive alcohol use was defined as current alcohol use of more than one drink per day for 1 year (12 ounces of beer with $5 \%$ alcohol, or 5 ounces of wine with $12 \%-15 \%$ alcohol, or one ounce of liquor with $45 \%-60 \%$ alcohol). All other patients were classified as negative alcohol use. experimental group) demonstrated low Annexin A1 expression, and 136 specimens (71 in the control group and 65 in the experimental group) exhibited high Annexin A1 expression. There was an equal distribution of Annexin A1 expression between the two groups (Chi-square test $=0.853, \mathrm{P}=0.356$ ). No significant difference of proportion of Annexin A1 expression was found according to baseline characteristics with exception of pathologic differentiation grade and alcohol use (Table 1). The proportion of patients with low Annexin A1 expression was higher amongst patients with moderate/poorly differentiated tumor (Figure 1) (78/167) and positive alcohol use (44/88) compared to those with well differentiated tumor (Figure 1) (18/65) and negative alcohol use (52/144), respectively There was no significant difference between pathologic differentiation grade and alcohol use $(\mathrm{P}=0.499)$.

\section{Annexin A1 expression and response to induction chemotherapy}

In the experimental group, responses by RECIST in 105 patients with assessment of Annexin A1 that initiated induction chemotherapy were: $78.1 \%$ clinical response (4 patients with complete response and 78 patients with partial response) and $18.1 \%$ clinical non-response (18 patients with stable disease and 1 patient with progressive disease), 4 patients were unevaluable for response. Favorable and unfavorable pathologic responses were observed in $26.7 \%(27 / 101)$ and $73.3 \%$ (74/101) of patients, respectively. Pathologic response could not be evaluated in 4 patients. Annexin A1 expression did not correlate with clinical response to TPF induction chemotherapy (Chisquare test $=1.073, \mathrm{P}=0.300$ ), or the pathologic response to induction chemotherapy (Chi-square test $=1.820$, $\mathrm{P}=0.177$ ) (Table 2), even when stratified according to alcohol use (Cochran's Mantel-Haenszel test $=0.313$, $\mathrm{P}=0.576$ for clinical response; Cochran's Mantel-Haenszel test $=0.488, \mathrm{P}=0.485$ for pathologic response).

\section{Annexin A1 expression and patients' outcomes}

No patients were lost to follow-up; the median followup time was 30 months among the censored patients. There was no significant difference on OS, DFS, LRFS or DMFS between the patients with and without TPF induction chemotherapy. The estimated 2-year OS was $68.2 \%$ and $68.8 \%$ in the patients with and without TPF induction chemotherapy, respectively. Locoregional recurrence and distant metastasis occurred in $30.9 \%$ and $7.0 \%$, respectively. In general, no significant difference was seen in locoregional recurrence or distant metastasis rates between the patients with and without TPF induction chemotherapy. However, in the experimental group, the patients with low Annexin A1 expression had a significantly lower local recurrence rate compared to that 
Table 2 Clinical and pathologic response to TPF induction chemotherapy according to Annexin A1 expression

\begin{tabular}{|c|c|c|c|}
\hline & \multicolumn{2}{|c|}{$\begin{array}{l}\text { Annexin A1 } \\
\text { expression }\end{array}$} & \multirow{2}{*}{$\begin{array}{l}\text { Chi-square } \\
\text { test } P \text { value }\end{array}$} \\
\hline & Low & High & \\
\hline Clinical response & 32 & 50 & \multirow[t]{2}{*}{0.300} \\
\hline Clinical non-response & 5 & 14 & \\
\hline Favorable pathologic response & 7 & 20 & \multirow{2}{*}{0.177} \\
\hline Unfavorable pathologic response & 30 & 44 & \\
\hline
\end{tabular}

A1 expression (low vs. high), lymph node status (cN0-1 vs. cN2, or cN0 vs. cN1-2), and clinical stage (stage III vs. stage IVA) were risk factors on OS, DFS, LRFS or DMFS. Multivariate Cox model analysis was performed using the risk factors of Annexin A1 expression and clinical stage; while lymph node status (cN0-1 vs. $\mathrm{cN} 2$ or cN0 vs. cN1-2) was not used because of the direct correlation between clinical stage and lymph node status. Both the clinical stage $(\mathrm{P}=0.001)$ and Annexin A1 expression $(\mathrm{P}=0.038)$ were independent risk factors. When pathologic differentiation grade and alcohol use were used in the multivariate Cox model analysis, only the clinical stage $(\mathrm{P}=0.001)$ and Annexin A1 expression $(\mathrm{P}=0.048)$ were independent risk factors.

\section{Annexin A1 expression, pathologic differentiation grade and patients' outcomes}

Patients with well differentiated tumor had a better outcome than those with moderate/poorly differentiated tumor. Pathologic differentiation grade did not have a significant effect on outcomes of the entire cohort with respect to OS $(\mathrm{P}=0.250)$, DFS $(\mathrm{P}=0.679)$, LRFS $(\mathrm{P}=0.790)$, and DMFS $(\mathrm{P}=0.260)$. In the experimental group, patients with well differentiated tumor had a better OS $(\mathrm{P}=0.958)$, DFS $(\mathrm{P}=0.711)$, LRFS $(\mathrm{P}=0.711)$, and DMFS $(\mathrm{P}=0.972)$ than those with moderate/poorly differentiated tumor. This was similar to the control group with respect to OS $(\mathrm{P}=0.132)$, DFS $(\mathrm{P}=0.415)$, LRFS $(\mathrm{P}=0.524)$, and DMFS $(\mathrm{P}=0.162)$.

In patients with well differentiated tumor, there was no significant difference in OS, DFS, LRFS or DMFS between patients treated with or without TPF induction chemotherapy, regardless of Annexin A1 expression. In patients with moderate/poorly differentiated tumor, low Annexin A1 expression benefited from TPF induction chemotherapy in OS $(\mathrm{P}=0.078, \mathrm{HR}=0.410)$ and DMFS $(\mathrm{P}=0.048, \mathrm{HR}=0.373)$ (Figure 3); however, patients with high Annexin A1 expression did not benefit from TPF induction chemotherapy. that the patients with low Annexin A1 expression had a better survival, especially the DFS $(\mathrm{P}=0.036, \mathrm{HR}=0.620)$ and LRFS ( $\mathrm{P}=0.031, \mathrm{HR}=0.607$ ) (Figure 2). Univariate Cox model was used to analyze the impact of baseline characteristics on the time-to-event endpoints; Annexin

\section{Discussion}

In this study, we found that Annexin A1 may be used as a prognostic biomarker in locally advanced and 
Table 3 Comparison of local/regional/distant failure between low and high Annexin A1 expression in the oral squamous cell carcinoma patients treated with or without TPF induction chemotherapy

\begin{tabular}{|c|c|c|c|c|}
\hline \multirow[t]{2}{*}{ Characteristics } & \multicolumn{2}{|c|}{ Annexin A1 expression } & \multirow{2}{*}{$\begin{array}{l}\text { Chi-square test } \\
\text { P value }\end{array}$} & \multirow{2}{*}{$\begin{array}{c}\text { Cochran Mantel Haenszel test } \\
\text { P value }\end{array}$} \\
\hline & Low & High & & \\
\hline \multicolumn{5}{|c|}{ Surgery+post-operative radiotherapy } \\
\hline No local failure & 45 & 52 & 0.348 & \\
\hline Local failure & 11 & 19 & & 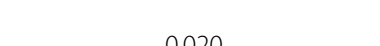 \\
\hline \multicolumn{5}{|c|}{ TPF+surgery+post-operative radiotherapy } \\
\hline No local failure & 37 & 47 & 0.012 & \\
\hline Local failure & 3 & 18 & & \\
\hline \multicolumn{5}{|c|}{ Surgery+post-operative radiotherapy } \\
\hline No regional failure & 51 & 60 & 0.268 & \\
\hline Regional failure & 5 & 11 & & 0323 \\
\hline \multicolumn{5}{|c|}{ TPF+surgery+post-operative radiotherapy } \\
\hline No regional failure & 34 & 54 & 0.795 & \\
\hline Regional failure & 6 & 11 & & \\
\hline \multicolumn{5}{|c|}{ Surgery+post-operative radiotherapy } \\
\hline No distant failure & 52 & 65 & 0.786 & \\
\hline Distant failure & 4 & 6 & & \\
\hline \multicolumn{5}{|c|}{ TPF+surgery+post-operative radiotherapy } \\
\hline No distant failure & 40 & 62 & 0.168 & \\
\hline Distant failure & 0 & 3 & & \\
\hline
\end{tabular}

resectable OSCC patients. Specifically, a lower Annexin A1 expression indicates improved survival. Annexin A1 expression correlates with pathologic differentiation grade of biopsy specimens from OSCC patients. A lower Annexin A1 expression correlates with a poorer differentiation grade. Furthermore, in patients with moderate/ poorly differentiated OSCC, those with low Annexin A1 expression may potentially benefit from TPF induction chemotherapy on the aspect of OS and DMFS, especially DMFS. Patients with low Annexin A1 expression may benefit from TPF induction chemotherapy compared to those with high Annexin A1 expression.

Although the precise mechanism of Annexin A1 in cancer development and progression is still not clearly understood, more emphasis has been placed on this protein in the field of carcinogenesis, cancer diagnosis and cancer treatment. Annexin A1 has been previously linked with various cancers as a tumor suppressor protein. This includes breast cancer, head neck cancer, prostate cancer, cervical cancer, lung cancer [11-19]. However, increased Annexin A1 expression has also been reported in breast cancer, bladder cancer, pancreatic cancer, liver cancer, esophageal cancer, lung cancer [20-27]. Recently, the prognostic value of Annexin A1 expression has been reported in lung cancer, head neck cancer, bladder cancer and breast cancer [18-24], most of which report Annexin
A1 overexpression indicates a poorer prognosis. In contrast, Annexin A1 overexpression in breast cancer correlates with a better survival [19]. In our study, a high Annexin A1 expression in the biopsy specimens indicated a poor prognosis, suggesting that Annexin A1 could be used as a prognostic biomarker for locally advanced OSCC. With respect to the role of Annexin A1 as a predictive biomarker for induction chemotherapy, future studies are necessary.

The correlation between Annexin A1 expression and pathologic differentiation grade has also been reported in several kinds of cancers, such as thyroid cancer, cervical cancer and head neck cancer [11-15,34]. In this study, we confirmed that the correlation between Annexin A1 expression and pathologic differentiation grade in OSCC. The proportion of patients with low Annexin A1 expression was higher amongst the patients with moderate/poorly differentiated tumor than those with well differentiated tumor. There was no significant difference between the pathologic differentiation grade and prognosis in both experimental and control groups. Radical removal of primary lesions as well as full neck dissection to eradicate as many lesions as possible may be an important factor for this result.

Correlation between Annexin A1 expression and response to induction chemotherapy has not been well 


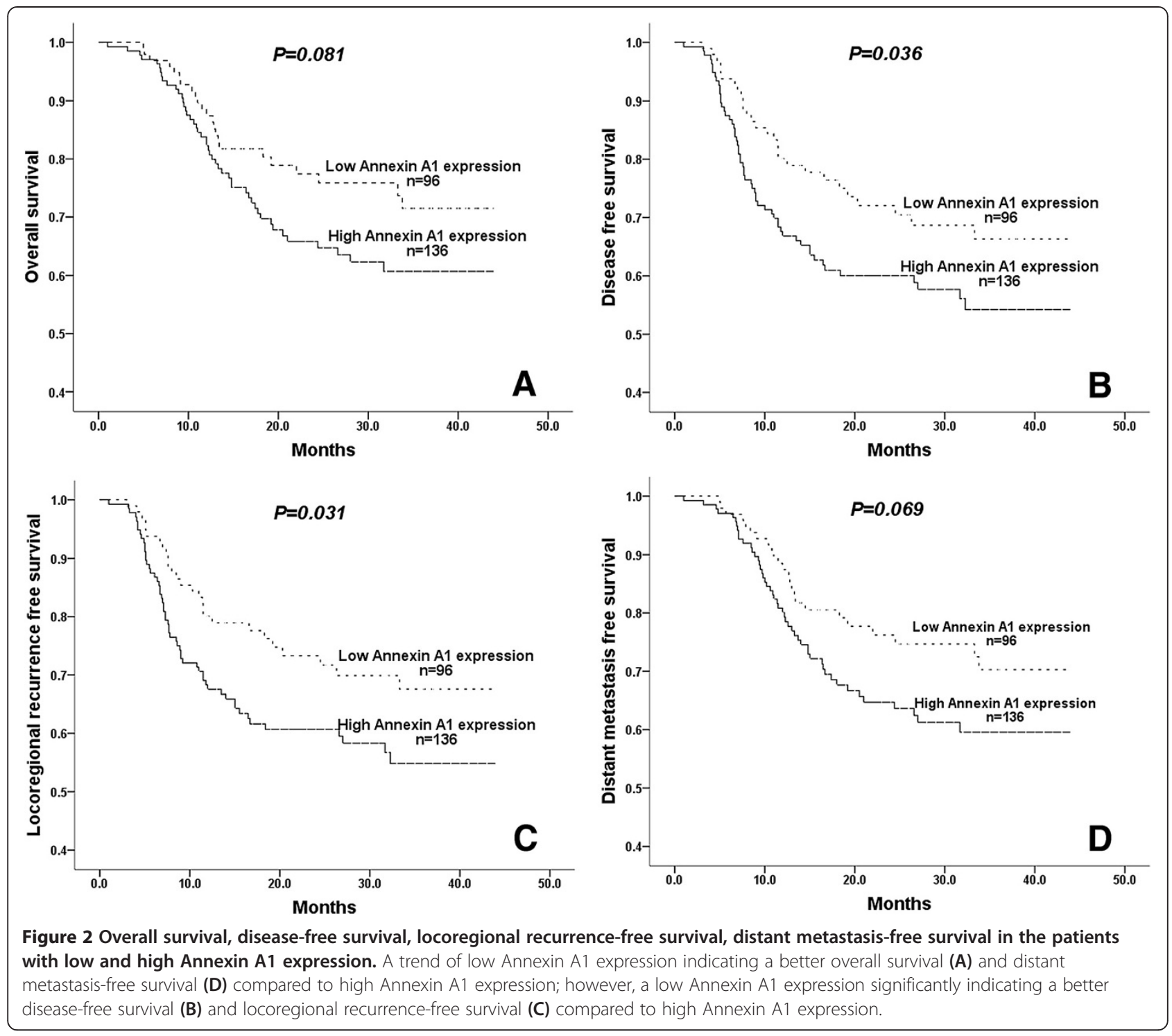

documented. Absence of Annexin A1 expression coupled with presence of Annexin A2 expression is reported to correlate with a poor pathological response to induction chemotherapy in breast cancer [28]. Increased Annexin A1 expression is reported to correlate with anti-cancer drug resistance in some tumor cells in vitro [35]. In this study, we failed to find a significant correlation between Annexin A1 expression and response to TPF induction chemotherapy in OSCC. Moreover, Annexin A1 was found to have limited utility as a predictive marker of clinical or pathologic response to TPF induction chemotherapy when we looked at the entire cohort of patients that received induction chemotherapy. However, a subgroup analysis showed that in the patients with moderate/poorly differentiated tumor, low Annexin A1 expression did have an OS and DMFS benefit from TPF induction chemotherapy. This suggests that detection of Annexin A1 expression prior to treatment can be used to guide treatment selection. One can envision a personalized treatment scenario in which OSCC patients with moderate/poorly differentiated tumor and low Annexin A1 expression receive TPF induction chemotherapy prior to surgery while those with high Annexin A1 expression, receive surgery to avoid the toxicity from chemotherapeutic agents and the delay of definitive treatment. A limitation of our study is a small sample size of 78 patients with low Annexin A1 expression who were used for subgroup analysis. As such, these results need to be considered exploratory and hypothesis generating, and clearly need to be confirmed in further clinical trials with larger sample sizes.

In addition to our findings related to Annexin A1 expression, other biomarkers have been evaluated as 


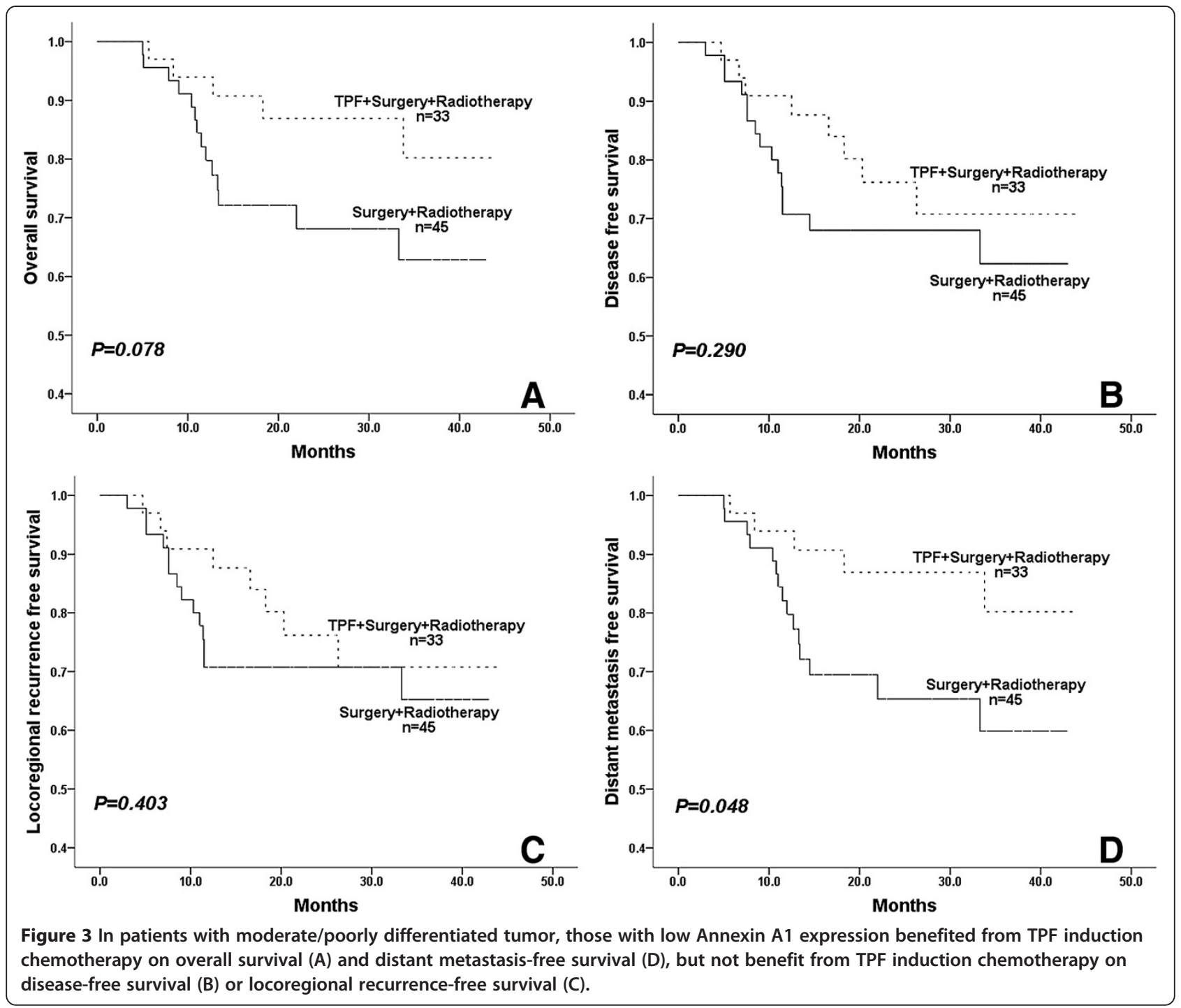

potential predictors of benefit from TPF induction treatment in HNSCC patients. Higher beta-Tubulin-II and lower cyclin D1 have been found to strongly associate with lower response rates to TPF induction chemotherapy $[36,37]$. However, before being widely embraced, further clinical trials on prognostic and/or predictive biomarkers, alone or in combination, are needed to validate their clinical utility, and to realize the goal of personalized treatment for patients with HNSCC.

\section{Conclusions}

Out studies suggest that Annexin A1 expression may serve as a prognostic biomarker in patients with resectable locally advanced OSCC. Furthermore, Annexin A1 is a predictive biomarker for response to TPF induction chemotherapy in patients with moderate/poorly differentiated OSCC.

\section{Competing interest}

The authors declare that they have no competing interests.

\section{Authors' contributions}

LZ was responsible for the study design, interpretation of the data and revision of the manuscript. DZ and $Y L$ were responsible for data acquisition analysis of the work presented and the preparation of the manuscript. $X$ Yang, CY, JM, X Yang, JQ, LW, JL, CZ and ZZ participated in the clinical management of the patients. All authors read and approved the final manuscript.

\section{Acknowledgements}

We thank Dr. Han-bing Fu and Dr. Ting Gu for providing technical support, and Dr. Dong-xia Ye for administrative assistance. This study was supported by research grant 2007BAl18B03 from National Key Technology R\&D Program of China; by research grants 30973344 and 81272979 from National Natural Science Foundation of China; by research grant 08QA14056 and 
13QH1401700 from Science and Technology Commission of Shanghai Municipality.

Received: 14 February 2013 Accepted: 18 June 2013

Published: 21 June 2013

\section{References}

1. Neville BW, Day TA: Oral cancer and precancerous lesions. CA Cancer J Clin 2002, 52:195-215.

2. Parkin DM, Bray F, Ferlay J, Pisani P: Global cancer statistics, 2002. CA Cancer J Clin 2005, 55:74-108.

3. Kademani D, Bell RB, Bagheri S, Holmgren E, Dierks E, Potter B, Homer L: Prognostic factors in intraoral squamous cell carcinoma: the influence of histologic grade. J Oral Maxillofac Surg 2005, 63:1599-1605.

4. Arduino PG, Carrozzo M, Chiecchio A, Broccoletti R, Tirone F, Borra E, Bertolusso G, Gandolfo S: Clinical and histopathologic independent prognostic factors in oral squamous cell carcinoma: a retrospective study of 334 cases. J Oral Maxillofac Surg 2008, 66:1570-1579.

5. Bell RB, Kademani D, Homer L, Dierks EJ, Potter BE: Tongue cancer: Is there a difference in survival compared with other subsites in the oral cavity? J Oral Maxillofac Surg 2007, 65:229-236.

6. Posner MR, Hershock DM, Blajman CR, Mickiewicz E, Winquist E, Gorbounova V, Tjulandin S, Shin DM, Cullen K, Ervin TJ, Murphy BA, Raez LE, Cohen RB, Spaulding M, Tishler RB, Roth B, Viroglio Rdel C, Venkatesan V, Romanov I, Agarwala S, Harter KW, Dugan M, Cmelak A, Markoe AM, Read PW, Steinbrenner L, Colevas AD, Norris CM Jr, Haddad RI, TAX 324 Study Group: Cisplatin and fluorouracil alone or with docetaxel in head and neck cancer. N Engl J Med 2007, 357:1705-1715.

7. Vermorken BJ, Remenar E, Herpen VC, Gorlia T, Mesia R, Degardin M, Stewart JS, Jelic S, Betka J, Preiss JH, van den-Weyngaert D, Awada A, Cupissol D, Kienzer HR, Rey A, Desaunois I, Bernier J, Lefebvre JL, EORTC 24971/TAX 323 Study Group: Cisplatin, fluorouracil, and docetaxel in unresectable head and neck cancer. N Engl J Med 2007, 357:1695-1704.

8. Lorch JH, Goloubeva O, Haddad Rl, Cullen K, Sarlis N, Tishler R, Tan M, Fasciano J, Sammartino DE, Posner MR, TAX 324 Study Group: Induction chemotherapy with cisplatin and fluorouracil alone or in combination with docetaxel in locally advanced squamous-cell cancer of the head and neck: long-term results of the TAX 324 randomised phase 3 trial. Lancet Oncol 2011, 12:153-159.

9. Zhong LP, Zhang CP, Ren GX, Guo W, William WN Jr, Sun J, Zhu HG, Tu WY, Li J, Cai YL, Wang LZ, Fan XD, Wang ZH, Hu YJ, Ji T, Yang WJ, Ye WM, Li J, He Y, Wang YA, Xu LQ, Wang BS, Kies MS, Lee JJ, Myers JN, Zhang ZY: Randomized phase III trial of induction chemotherapy with docetaxel, cisplatin and fluorouracil followed by surgery versus up-front surgery in locally advanced resectable oral squamous cell carcinoma. J Clin Oncol 2013, 31:744-751.

10. Lim LH, Pervaiz S: Annexin 1: the new face of an old molecule. FASEB J 2007, 21:968-975.

11. Petrella A, Festa M, Ercolino SF, Zerilli M, Stassi G, Solito E, Parente L: Annexin-1 downregulation in thyroid cancer correlates to the degree of tumor differentiation. Cancer Biol Ther 2006, 5:643-647.

12. Wang LD, Yang YH, Liu Y, Song HT, Zhang LY, Li PL: Decreased expression of annexin A1 during the progression of cervical neoplasia. J Int Med Res 2008, 36:665-672.

13. Hu N, Flaig MJ, Su H, Shou JZ, Roth MJ, Li WJ, Wang C, Goldstein AM, Li G, Emmert-Buck MR, Taylor PR: Comprehensive characterization of annexin I alterations in esophageal squamous cell carcinoma. Clin Cancer Res 2004, 10:6013-6022

14. Garcia Pedrero JM, Fernandez MP, Morgan RO, Morgan RO, Herrero Zapatero A, Gonzalez MV, Suarez Nieto C, Rodrigo JP: Annexin A1 downregulation in head and neck cancer is associated with epithelial differentiation status. Am J Pathol 2004, 164:73-79.

15. Nomura H, Uzawa K, Yamano Y, Fushimi K, Nakashima D, Kouzu Y, Kasamatsu A, Ogawara K, Shiiba M, Bukawa H, Yokoe H, Tanzawa H: Downregulation of plasma membranous Annexin A1 protein expression in premalignant and malignant lesions of the oral cavity: correlation with epithelial differentiation. J Cancer Res Clin Oncol 2009, 135:943-949.

16. Shen D, Nooraie F, Elshimali Y, Lonsberry V, He J, Bose S, Chia D, Seligson D, Chang HR, Goodglick L: Decreased expression of annexin A1 is correlated with breast cancer development and progression as determined by a tissue microarray analysis. Hum Pathol 2006, 37:1583-1591.
17. Kang JS, Calvo BF, Maygarden SJ, Caskey LS, Mohler JL, Ornstein DK: Dysregulation of annexin I protein expression in high-grade prostatic intraepithelial neoplasia and prostate cancer. Clin Cancer Res 2002, 8:117-123.

18. Yom CK, Han W, Kim SW, Kim HS, Shin HC, Chang JN, Koo M, Noh DY, Moon Bl: Clinical significance of annexin A1 expression in breast cancer. J Breast Cancer 2011, 14:262-268.

19. Wang LP, Bi J, Yao C, Li XX, Wang SM, Li ZL, Zhang DY, Wang M, Chang GQ: Annexin A1 expression and its prognostic significance in human breast cancer. Neoplasma 2010, 57:253-259.

20. Lin CY, Jeng YM, Chou HY, Li QQ, Chen ZC: Nuclear localization of annexin A1 is a prognostic factor in oral squamous cell carcinoma. J Surg Oncol 2008, 97:544-550.

21. Liu YF, Zhang PF, Li MY, Li QQ, Chen ZC: Identification of annexin A1 as a proinvasive and prognostic factor for lung adenocarcinoma. Clin Exp Metastasis 2011, 28:413-425.

22. Biaoxue R, Xiling J, Shuanying Y, Wei Z, Xiguang C, Jinsui W, Min Z: Upregulation of Hsp90-beta and annexin A1 correlates with poor survival and lymphatic metastasis in lung cancer patients. J Exp Clin Cancer Res 2012, 31:70.

23. Wang KL, Wu TT, Resetkova E, Wang H, Correa AM, Hofstetter WL, Swisher SG, Ajani JA, Rashid A, Hamilton SR, Albarracin CT: Expression of annexin A1 in esophageal and esophagogastric junction adenocarcinomas: association with poor outcome. Clin Cancer Res 2006, 12:4598-4604.

24. Li CF, Shen KH, Huang LC, Huang HY, Wang YH, Wu TF: Annexin-I overexpression is associated with tumour progression and independently predicts inferior disease-specific and metastasis-free survival in urinary bladder urothelial carcinoma. Pathology 2010, 42:43-49.

25. Bai XF, Ni XG, Zhao P, Liu SM, Wang HX, Guo B, Zhou LP, Liu F, Zhang JS, Wang $K$, Xie YQ, Shao YF, Zhao XH: Overexpression of annexin 1 in pancreatic cancer and its clinical significance. World J Gastroenterol 2004, 10:1466-1470.

26. Guzman-Aranguez A, Olmo N, Turnay J, Lecona E, Perez-Ramos P, Lopez de Silanes I, Lizarbe MA: Differentiation of human colon adenocarcinoma cells alters the expression and intracellular localization of annexins A1, A2, and A5. J Cell Biochem 2005, 94:178-193.

27. Masaki T, Tokuda M, Ohnishi M, Watanabe S, Fujimura T, Miyamoto K, Itano T, Matsui H, Arima K, Shirai M, Maeba T, Sogawa K, Konishi R, Taniguchi K, Hatanaka Y, Hatase O, Nishioka M: Enhanced expression of the protein kinase substrate annexin in human hepatocellular carcinoma. Hepatology 1996, 24:72-81.

28. Chuthapisith S, Bean BE, Cowley G, Eremin JM, Samphao S, Layfield R, Kerr ID, Wiseman J, El-Sheemy M, Sreenivasan T, Eremin O: Annexins in human breast cancer: Possible predictors of pathological response to neoadjuvant chemotherapy. Eur J Cancer 2009, 45:1274-1281.

29. Therasse P, Arbuck SG, Eisenhauer EA, Wanders J, Kaplan RS, Rubinstein L, Verweij J, Van-Glabbeke M, van-Oosterom AT, Christian MC, Gwyther SG: New guidelines to evaluate the response to treatment in solid tumors. European Organization for Research and Treatment of Cancer, National Cancer Institute of the United States, National Cancer Institute of Canada. J Natl Cancer Inst 2000, 92:205-216.

30. Licitra L, Grandi C, Guzzo M, Mariani L, Lo Vullo S, Valvo F, Quattrone P, Valagussa P, Bonadonna G, Molinari R, Cantu G: Primary chemotherapy in resectable oral cavity squamous cell cancer: a randomized controlled trial. J Clin Oncol 2003, 21:327-333.

31. Barnes L, Eveson JW, Reichart P, Sidransky D: World Health Organization Classification of Tumours. Pathology and Genetics of Head and Neck Tumours. Lyon: IARC Press; 2005:168-175.

32. Zhong LP, Wei KJ, Yang X, Pan HY, Wang LZ, Zhang ZY: Overexpression of Galectin-1 is positively correlated with pathologic differentiation grade in oral squamous cell carcinoma. J Cancer Res Clin Oncol 2010, 136:1527-1535.

33. Zhang L, Yang X, Pan HY, Zhou XJ, Li J, Chen WT, Zhong LP, Zhang ZY: Expression of growth differentiation factor 15 is positively correlated with histopathological malignant grade and in vitro cell proliferation in oral squamous cell carcinoma. Oral Oncol 2009, 45:627-632.

34. Zhang L, Yang X, Zhong LP, Zhou XJ, Pan HY, Wei KJ, Li J, Chen WT, Zhang $Z Y$ : Decreased expression of Annexin A1 correlates with pathologic differentiation grade in oral squamous cell carcinoma. J Oral Pathol Med 2009, 38:362-370.

35. Wang Y, Serfass L, Roy MO, Wong J, Bonneau AM, Georges E: Annexin-I expression modulates drug resistance in tumor cells. Biochem Biophys Res Commun 2004, 314:565-570. 
36. Zhong LP, Zhu DW, William WN Jr, Liu Y, Ma J, Yang CZ, Yang X, Wang LZ, Li J, Myers JN, Lee JJ, Zhang CP, Zhang ZY: Elevated cyclin D1 expression is predictive for a benefit from TPF induction chemotherapy in oral squamous cell carcinoma patients with advanced nodal disease. Mol Cancer Ther 2013, 12:1112-1121.

37. Cullen KJ, Schumaker L, Nikitakis N, Goloubeva O, Tan M, Sarlis NJ, Haddad Rl, Posner MR: Beta-Tubulin-Il expression strongly predicts outcome in patients receiving induction chemotherapy for locally advanced squamous carcinoma of the head and neck: a companion analysis of the TAX 324 trial. J Clin Oncol 2009, 27:6222-6228.

doi:10.1186/1471-2407-13-301

Cite this article as: Zhu et al:: Low Annexin A1 expression predicts benefit from induction chemotherapy in oral cancer patients with moderate or poor pathologic differentiation grade. BMC Cancer 2013 13:301.

\section{Submit your next manuscript to BioMed Central and take full advantage of:}

- Convenient online submission

- Thorough peer review

- No space constraints or color figure charges

- Immediate publication on acceptance

- Inclusion in PubMed, CAS, Scopus and Google Scholar

- Research which is freely available for redistribution 